\title{
Deep Insight Into Long Non-Coding RNA and mRNA Transcriptome Profiling in HepG2 Cells Expressing Genotype IV Swine Hepatitis E Virus ORF3
}

Hanwei Jiao ( $D$ 366045252@qq.com )

Southwest University https://orcid.org/0000-0001-8001-8697

Xuehong Shuai

Southwest University

Yichen Luo

Southwest University

Zhixiong Zhou

Southwest University

Yu Zhao

Southwest University

Wenjie Li

Southwest University

\section{Bowen Li}

Southwest University

Guojing Gu

Southwest University

Li Wu

Southwest University

Xianmei Luo

Southwest University

Ling Gan

Southwest University

Jixuan Chen

Southwest University

Qingzhou Huang

Southwest University

Research article

Keywords: SHE, SHEV, ORF3, IncRNA, HepG2 
Posted Date: October 7th, 2020

DOl: https://doi.org/10.21203/rs.3.rs-72773/v1

License: (c) (i) This work is licensed under a Creative Commons Attribution 4.0 International License. Read Full License 


\section{Abstract}

Background: Swine hepatitis $E$ (SHE) is a new type of zoonotic infectious disease caused by swine hepatitis E virus (SHEV). Open reading frame 3 (ORF3) is an important virulent protein of SHEV but its function still is mainly unclear.

Methods: In this study we generated adenoviruses ADV4-ORF3 and ADV4-NC which successfully mediated overexpression of EGFP-ORF3 and EGFP, respectively, in HepG2 cells. High throughput sequencing was used to screen for differentially expressed long non-coding RNAs (IncRNAs) and mRNAs. The cis-target genes of IncRNAs were predicted, functional enrichment (Gene ontology (GO) and Kyoto Encyclopedia of Genes and Genomes (KEGG)) was performed, and 12 IncRNAs with statistically significant different expression ( $p$ value $\leq 0.05$ and $q$ value $\leq 1$ ) were selected for further quantitative real-time reverse transcription (qRT-PCR) validation.

Results: In HepG2 cells, we identified 62 significantly differential expression genes (DEGs) $(6,564$ transcripts), and 319 IncRNAs (124 known IncRNAs and 195 novel IncRNAs) that were affected by ORF3, which were involved in systemic lupus erythematosus, staphylococcus aureus infection, signaling pathways regulating pluripotency of stem cells, the PPAR signaling pathway, and platinum drug resistance pathways. Cis-target gene prediction identified 45 IncRNAs corresponding to candidate mRNAs, among which 8 were validated by qRT-PCR: LINC02476 (two transcripts), RAP2C-AS1, AC016526, AL139099, and ZNF337-AS1 (3 transcripts).

Conclusions: Our results revealed the IncRNA profile in host cells affected by ORF3, which will help to determine the function of ORF3, and the infection mechanism and treatment of SHE.

\section{Background}

Hepatitis E (HE) caused by hepatitis E virus (HEV) is a new type of zoonotic infectious disease. HEV is mainly transmitted through the fecal-oral route, can cause acute hepatitis in humans, and it is prevalent worldwide [1-3]. About 20 million people are infected with HEV every year. In addition to the clinical symptoms of hepatitis, it also causes nerve, blood, and kidney diseases, neuralgia muscular atrophy, encephalitis, myelitis, and other diseases [4]. Studies have shown that the continuous glycine motif in the $\beta$ chain of HEV specific T cell receptors (TCRs) pathway might be the target for TCR binding heterozygosity recognition, thus promoting cross recognition, which might develop into a candidate for Tcell therapy for chronic HE [5].

Swine hepatitis $E$ (SHE) is caused by swine hepatitis E virus (SHEV). In recent years, outbreaks of SHE have appeared globally and have become a public health issue in various countries [6, 7]. SHEV belongs to the family Hepeviridae [8]. Genotype IV is mainly prevalent in China. Its genome comprises about $7.6 \mathrm{~kb}$, with a poly A tail structure at the $3^{\prime}$ end and three overlapping open reading frames (ORF): ORF1, ORF2, and ORF3 $[9,10]$. 
The ORF3 protein (hereafter referred to as ORF3) is a small and poorly characterized protein that is involved in the secretion of virus particles and other functions. Palmitoylation determines the subcellular location, membrane topology, and function of ORF3 in the life cycle of HEV [11]. ORF3 forms polymer complexes related to endoplasmic reticulum (ER)-derived membranes through affinity interaction, which might be an attractive target for the development of antiviral drugs [12]. ORF3 significantly inhibits the activity of the nuclear factor kappa-B (NF-KB) signaling pathway, mediated by pattern-recognition receptors (PRRs), thus providing a breakthrough point for clarifying the function of ORF3 in chronic HEV infection and cirrhosis [13]. ORF3 mediates the regulation of endosomal sorting complexes required for transport (ESCRT) through the "PSAP" motif (viral late domain) [14].

Although the function of HEV ORF3 has been studied, the function of SHEV ORF3 remains unclear. In the present study, we used adenovirus mediated overexpression of genotype IV SHEV ORF3 in HepG2 cells, and performed transcriptome sequencing to identify significantly differentially expressed long non-coding RNAs (IncRNAs) and their target genes affected by ORF3, which form a basis to reveal the function of ORF3, explain the interaction mechanism between SHEV and target cells, and provide a scientific basis for the prevention and treatment of SHE.

\section{Methods}

\section{Cell Lines}

HepG2, 293A, and 293T cells were purchased from the Shanghai cell bank of the Chinese Academy of Science, and cultured at $37^{\circ} \mathrm{C}, 5 \% \mathrm{CO}_{2}$ in Dulbecco's modified Eagle's medium (DMEM) (Life technology, Carlsbad, CA, USA) containing 10\% fetal bovine serum (Life technology) supplemented with 10\% penicillin $(100 \mathrm{U} / \mathrm{mL})$ and streptomycin $(100 \mu \mathrm{g} / \mathrm{mL})$ (both Life technology).

\section{Preparation of Recombinant Adenovirus ADV4-ORF3 and ADV4-NC}

Sangon Biotech (Shanghai, China) Co., Ltd synthesized the ORF3 gene (345 bp) of genotype 4 swine hepatitis E virus (SHEV). Adenoviruses ADV4-ORF3 and ADV4-NC were generated by Shanghai GenePharma Co, Ltd (Shanghai, China). The EGFP protein was fused to the N-terminus of ORF3. Both of them were sequenced using Sanger sequencing and no mutations compared with the published sequence of ORF3 and the rest of the plasmid were found. Briefly, EcoR I and BamH I were added to the upstream and downstream primers of the target gene respectively. SHEV-ORF3 was cloned into vector ADV4 (CMV/IRES-GFP) (Fig.S1), this vector, with a molecular weight of 7,500 bp, comprises a CMV promoter, a multiple cloning site, GFP, IRES, an ampicillin resistant gene, and the Ad5 skeleton. Highly pure and non-toxic recombinant expression shuttle plasmid ADV4-ORF3 and framework plasmid pGP-AdPac were prepared. The shuttle plasmids ADV4ORF3, ADV4-negative control (ADV4-NC), and framework plasmid pGP-Ad-Pac (molecular weight of 35,000 bp, comprising of Ori promoter, pA, Ampicillin resistance gene, dE3 and Ad5 skeleton (Fig. S2)), were co-transfected into 293A cells with the RNAi mate 
transfection reagent (GenePharma, Shanghai, China). Six hours after transfection, the culture medium was replaced with complete medium, and fresh medium was supplemented every seven days. Then, the cells and supernatant were collected and placed in a centrifuge tube, frozen and thawed three times, centrifuged at $800 \times \mathrm{g}$ for five minutes, and the supernatant was regarded as the primary adenovirus solution. After three successive generations of repeated amplification and collection of adenovirus, a large amount of adenovirus was obtained, which was then purified and concentrated to obtain a high titer of recombinant adenovirus concentrate.

The ADV4-ORF3 and ADV4-NC adenovirus titers were determined in 293T cells. Briefly, 293T cells were added to a 96 -well plate at $10^{4}$ cells per well. The amount of medium added was $200 \mu$ l. The plate was incubated in incubator for $24 \mathrm{~h}$, and the adenovirus to be tested was diluted to $10^{-2}, 10^{-3}, 10^{-4}, 10^{-5}, 10^{-}$ 6 , and $10^{7}$ with complete medium. After aspirating off the supernatant, the adenovirus solutions at different dilutions were added at $200 \mu \mathrm{l}$ per well. Samples were repopulated, and culture medium without adenovirus was set as a control. The plates were incubated at $37^{\circ} \mathrm{C}, 5 \% \mathrm{CO}_{2}$. The culture continued for 36-48 $\mathrm{h}$ under $\mathrm{CO}_{2}$ conditions. The cytopathic effect (CPE) was observed using microscopy, and the virus titer was calculated according to a formula supplied by Baxter Healthcare Corporation (Round Lake, IL, USA).

\section{Infection Assay of Recombinant Adenovirus ADV4-ORF3 and ADV4-NC}

HepG2 cells were seeded into a 12-well plate $\left(1 \times 10^{6}\right.$ cells/well), infected with ADV4-ORF3 and ADV4-NC at $12 \mathrm{~h}$ postseeding at a multiplicity of infection (MOI) of 5:1. The cells were harvested after infection for $24 \mathrm{~h}$. Then, $0.8 \mu \mathrm{L}$ of polybrene was added to each well to improve the transfection efficiency. Triplicate infection experiments were performed. QRT-PCR was used to confirm ORF3 overexpression. The sequences of the primers were as follows:

ORF3: forward primer: 5'-GCTCCTCCTGCTTTTGCCTA-3', reverse primer: 5'-GCTGAGAATCAACCCGGTCA$3^{\prime}$,

GAPDH: forward primer: 5'-GCTCTCTGCTCCTCCTGTTC-3', reverse primer: 5'CCAAATCCGTTGACTCCGAC-3'.

The sample of ADV4-ORF3 infected cells was named Ad_ORF3, and the ADV4-NC infected cells were named Ad_GFP.

\section{RNA Sample Preparation and Transcriptome Sequencing}

Total RNA was extracted and purified using the Trizol reagent (Invitrogen, Carlsbad, CA, USA) following the manufacturer's procedure. The RNA amount and purity of Ad_GFP_1, Ad_GFP_2, Ad_GFP_3, Ad_ORF3_1, Ad_ORF3_2, and Ad_ORF3_3 samples were quantified using a NanoDrop ND-1000 instrument (NanoDrop, Wilmington, DE, USA). The RNA integrity was assessed using an Agilent 2100 with an RNA integrity number $(\mathrm{RIN})>7.0$. Approximately $5 \mu \mathrm{g}$ of total RNA was used to deplete ribosomal RNA 
according to the protocol of the Ribo-Zero ${ }^{\mathrm{TM}}$ rRNA Removal Kit (Illumina, San Diego, CA, USA). After removing ribosomal RNAs, the remaining RNAs were fragmented into small pieces using divalent cations under high temperature. Then, the cleaved RNA fragments were reverse-transcribed to create the cDNA using ProtoScript II Reverse Transcriptase and First Strand Synthesis Mix (Ambion, Austin, TX, USA), which were next used to synthesize U-labeled second-stranded DNAs with E. coli DNA polymerase I, RNase $\mathrm{H}$, and dUTP. An A-base was then added to the blunt ends of each strand, preparing them for ligation to the indexed adapters. Each adapter contained a T-base overhang for ligating to the A-tailed fragmented DNA. Single-or dual-index adapters were ligated to the fragments, and size selection was performed using AMPureXP beads. After heat-labile UDG enzyme treatment of the U-labeled secondstranded DNAs, the ligated products are amplified by PCR using the following conditions: Initial denaturation at $95^{\circ} \mathrm{C}$ for $3 \mathrm{~min}$; eight cycles of denaturation at $98^{\circ} \mathrm{C}$ for $15 \mathrm{sec}$, annealing at $60^{\circ} \mathrm{C}$ for 15 sec, and extension at $72{ }^{\circ} \mathrm{C}$ for $30 \mathrm{sec}$; and then final extension at $72{ }^{\circ} \mathrm{C}$ for $5 \mathrm{~min}$. The average insert size for the final cDNA library was $300 \mathrm{bp}( \pm 50 \mathrm{bp}$ ). Finally, we performed paired-end sequencing on an Illumina Hiseq 4000 sequencer ( LC Bio, Hangzhou, China).

\section{Preparation of Polyclonal Antibodies Against ORF3 and Western-blot}

Genotype IV Swine Hepatitis E Virus ORF3 gene was synthesized by Biotechnology (Shanghai) Co., Ltd, we designed the prokaryotic expression prime, forward primer: $5^{\prime}-$

CGCTGAATTCATGGCGATGCCACCATGCG-3', reverse primer: 5'-GCCTAAGCTTTCAGCGGCGAAGCCCCAG3 ', and used pET-28a (+) for construction prokaryotic vector of pET28-ORF3. The recombinant plasmid was transformed into BL21 competent cells, which were induced by $0.1 \mathrm{mmol} / \mathrm{L} \mathrm{IPTG}$ for $6 \mathrm{~h}$ at $37^{\circ} \mathrm{C}$, and the cell was broken by ultrasound to collect ORF3 antigen. After SDS-PAGE electrophoresis, the target protein was cut off and used to immunize male New Zealand white rabbits. $375 \mu \mathrm{g}$ of ORF3 protein was used to inject rabbits for the first immunization, the same method was used for the second and third injection after another two 14 days. Ten days after the last immunization, blood was collected from the heart to isolate the antiserum, and the titer of antiserum was detected by indirect ELISA.

HepG2 cells were infected with the high titer recombinant adenovirus of ADV4-NC (control) and ADV4ORF3 for $24 \mathrm{~h}$. The cells were collected and lysed with RIPA containing $1 \mu \mathrm{g} / \mathrm{ml} \mathrm{PMSF.} 40 \mu \mathrm{g}$ of total protein was analyzed by $15 \%$ SDS-PAGE and electrically transferred to PVDF membrane for $1.5 \mathrm{~h}$, which blocked with $5 \%$ skimmed milk for $2 \mathrm{~h}$, washed three times with TBST, and incubated with antiORF3 primary antibody (1:200 dilution) at $4{ }^{\circ} \mathrm{C}$ overnight and a monoclonal mouse anti- $\beta$-actin (1:2000 dilution; Santa Cruz Biotechnology, USA), the PVDF membrane washed three times with TBST, incubated

with horseradish peroxidase (HRP)-labeled goat anti-rabbit IgG (1:5000 dilution; Abcam, USA) and mouseIgGk BP-HRP (1:5000 dilution; Santa Cruz Biotechnology, USA) for $2 \mathrm{~h}$, and washed threes with TBST. The PVDF membrane was developed with super signal ${ }^{\text {Tw }}$ west pico plus chemiluminescent substrate kit (Thermo Scientific, USA), and the ORF3 and $\beta$-actin proteins were detected by CCD cameras.

\section{Differentially Expressed IncRNAs and mRNAs Analysis}


Firstly, Cutadapt [15] was used to remove the reads that contained adaptor contamination, low quality bases, and undetermined bases. The sequence quality was then verified using FastQC (http://www.bioinformatics.babraham.ac.uk/projects/fastqc/). We used Bowtie2 [16] and Hisat2 [17] to map reads to the human genome. The mapped reads of each sample were assembled using StringTie [18]. Then, all the transcriptomes from Ad_GFP_1, Ad_GFP_2, Ad_GFP_3, Ad_ORF3_1, Ad_ORF3_2, and Ad_ORF3_3 samples were merged to reconstruct a comprehensive transcriptome using perl scripts. After the final transcriptome was generated, StringTie and edgeR [19] were used to estimate the expression levels of all transcripts.

Transcripts that overlapped with known mRNAs and transcripts shorter than 200 bp were discarded. Then we utilized the coding potential calculator (CPC) [20] and coding-non-coding index (CNCl) [21] to predict transcripts with coding potential. All transcripts with a CPC score $<-1$ and $\mathrm{CNCl}$ score $<0$ were removed. The remaining transcripts were considered as IncRNAs. Differential expression analysis of mRNAs and IncRNAs used StringTie to perform expression level analyses for mRNAs and IncRNAs by calculating the FPKM [22]. FPKM can represent the expression of IncRNAs. In the present study we identified five class codes defining IncRNAs: Class code $\mathrm{j}$ indicated potentially novel isoforms (fragments), in which at least one splice junction is shared with a reference transcript; class code i indicated a transfragment falling entirely within a reference intron; class code o indicated generic exonic overlap with a reference transcript; class code $u$ indicated an unknown, intergenic transcript; and class code $\mathrm{x}$ indicated exonic overlap with a reference on the opposite strand. The differentially expressed mRNAs and IncRNAs were selected using $\log 2$ (fold change) $>1$ or log2 (fold change) $<-1$ and with statistical significance ( $p$ value $<0.05$ ) using the $\mathrm{R}$ package module edgeR [19].

\section{Target gene prediction and functional analysis of IncRNAs}

To explore the function of the IncRNAs, we predicted their cis-target genes. In this study, coding genes in the $100 \mathrm{kbp}$ regions upstream and downstream of the IncRNA were selected using a python script. Then, we performed functional analysis of the IncRNA target genes using BLAST2GO [23]. Significance was expressed as a $p$ value $<0.05$.

\section{Quantitative Reverse Transcription PCR (qRT-PCR) Validation}

The primers were designed using NCBI Primer online software. Approximately $1 \mu \mathrm{g}$ of total RNA was used for reverse transcription using a PrimeScript ${ }^{\text {'" }}$ RT reagent kit (Takara, Shiga, Japan), and validation by qRT-PCR was performed using TB Green ${ }^{\circledR}$ Premix Ex Taq ${ }^{\text {T' }}$ II (Tli RNaseH Plus) (Takara). GAPDH was used as an internal control. The primers are listed in Table 1. The relative expression levels of IncRNAs and mRNAs were determined using the $2^{-\Delta \Delta C t}$ method. Three independent replicates were performed. Student's t-test was used for statistical analysis. $p<0.05$ was considered statistically significant,

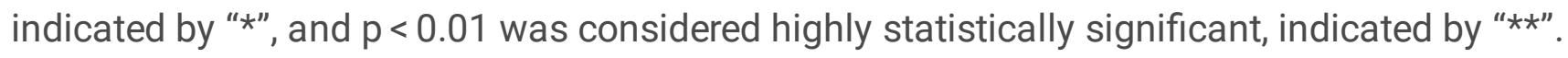


Table 1

Primers for the selected significantly differentially expressed IncRNAs ( $p$ value $\leq 0.05$ and $q$ value $\leq 1)$ for qRT-PCR validation.

\begin{tabular}{|c|c|c|}
\hline IncRNAs_name & Transcripts_name & Primer Sequence $\left(5^{\prime}-3^{\prime}\right)$ \\
\hline \multirow[t]{2}{*}{ PLCG1-AS19 } & ENST00000454626 & F: CTGCCTCACAGGAGATCCAC \\
\hline & & R: CAGCCTTGGCCATCCTCATT \\
\hline \multirow[t]{2}{*}{ AL139099 } & ENST00000555043 & F: CTTCCTTTGTCGCCCATTGC \\
\hline & & R: AGCTGTAGCTGCGCTCCC \\
\hline \multirow[t]{2}{*}{ AC005062 } & ENST00000449573 & F: TACTGGAAGATGGCGGTTCC \\
\hline & & R:GAGACAGAAAGCGGAGTCTCA \\
\hline \multirow[t]{2}{*}{ FP236383 } & ENST00000625598 & F: AACGCCACTTGTCCCTCTAA \\
\hline & & R: ACACGGACAGGATTGACAGA \\
\hline \multirow[t]{2}{*}{ FP671120 } & ENST00000627981 & F: AACGCCACTTGTCCCTCTAA \\
\hline & & R: ACACGGACAGGATTGACAGA \\
\hline \multirow[t]{2}{*}{ FP671120 } & ENST00000631211 & F: AACGCCACTTGTCCCTCTAA \\
\hline & & R: ACACGGACAGGATTGACAGA \\
\hline \multirow[t]{2}{*}{ ZNF337-AS1 } & ENST00000428254 & F: AAGCGTGGTGTTCTTCCCTG \\
\hline & & R: CAGCATCCGCACAACAATGG \\
\hline \multirow[t]{2}{*}{ ZNF337-AS1 } & ENST00000455791 & F: CCCGCGATCTGTCTCATTCC \\
\hline & & R: GGGCACAGGTAGGTGGTTAG \\
\hline \multirow[t]{2}{*}{ ZNF337-AS1 } & ENST00000420803 & F: CAАCTACСТССССТGTGCAA \\
\hline & & R: TTGGAGCCATCTTTCGAGGC \\
\hline \multirow[t]{2}{*}{ ZNF337-AS1 } & ENST00000421829 & F: CTACCTCСССТGTGCAAGTT \\
\hline & & R: GGCACAGGTAGGTGGTTAGC \\
\hline \multirow[t]{2}{*}{ ZNF337-AS1 } & ENST00000414393 & F: CCCGCGATCTGTCTCATTCC \\
\hline & & R: TTGCACAGGGGAGGTAGTTG \\
\hline \multirow[t]{2}{*}{ ZNF337-AS1 } & ENST00000439498 & F: TGGAATTCCCGCGATCTGTC \\
\hline & & R: GGGCACAGGTAGGTGGTTAG \\
\hline \multirow[t]{2}{*}{ AP005329 } & ENST00000581905 & F: TCCTGTATGGTGCCTGGAGA \\
\hline & & R: AGGTGGACACCCTGTAGTTC \\
\hline
\end{tabular}




\begin{tabular}{|c|c|c|}
\hline IncRNAs_name & Transcripts_name & Primer Sequence $\left(5^{\prime}-3^{\prime}\right)$ \\
\hline \multirow[t]{2}{*}{ AP000977 } & ENST00000501964 & F: GTGCATGCAGGTGGCATTAG \\
\hline & & R: GGGACAGAGGGGGATATGGT \\
\hline \multirow[t]{2}{*}{ LINC02476 } & ENST00000431071 & F:АCTTTCCCTGGCAAACAAAAACA \\
\hline & & R:GCTTCCTAGGTAGGACAGGGA \\
\hline \multirow[t]{2}{*}{ LINC02476 } & ENST00000426413 & F:GGTGTCGAGCTGTGAATGAGA \\
\hline & & R:ATGGGATGGGGCTGGGTTAT \\
\hline \multirow[t]{2}{*}{ RAP2C-AS1 } & ENST00000441399 & F:ACTTAGCCGTGCCTGACAAA \\
\hline & & R:GCTCCAAAAAGGCACCCTTG \\
\hline \multirow[t]{2}{*}{ RAP2C-AS1 } & ENST00000421483 & F:CAAGGGTGCCTTTTTGGAGC \\
\hline & & R:AAGAGCTTGATGACTCCGGC \\
\hline \multirow[t]{2}{*}{ AC107959 } & ENST00000502083 & F:TGCTCTGTCTGGCCAAATCC \\
\hline & & R:CCCATGTGAAGCATTGCCTG \\
\hline \multirow[t]{2}{*}{ AC107959 } & ENST00000523884 & F:TCTTCACCACCACCATCAGC \\
\hline & & R:GCCGAGCTTTTGTGAGCATC \\
\hline \multirow[t]{2}{*}{ AC016526 } & ENST00000554225 & F:CACACTGGCCTTAGGGTGAC \\
\hline & & R:ACGTCTTTGTGAAGTCGGCA \\
\hline
\end{tabular}

\section{Results}

\section{Recombinant adenovirus-mediated overexpression of ORF3}

HepG2 cells were infected with the high titer recombinant adenovirus of ADV4-NC (control) and ADV4ORF3 for $24 \mathrm{~h}$. Enhanced green fluorescent protein (EGFP) expression was detected using fluorescence microscopy. The results showed that EGFP and the EGFP-ORF3 fusion protein were successfully expressed in HepG2 cells (Fig. 1a). Quantitative real-time reverse transcription PCR (qRTPCR) was used to detect the relative expression of ORF3 RNA, with GAPDH (encoding glyceraldehyde-3phosphate dehydrogenase) used as the internal control. The results demonstrated that the recombinant adenovirus successfully mediated the overexpression of ORF3 (Fig. 1b).

The indirect ELISA results showed that polyclonal antibody titer reached 1:12800. Western blot was performed on equal amounts of $40 \mu \mathrm{g}$ protein extracted from Ad_GFP and Ad_ORF3. $\beta$-actin was used for an internal control. With rabbit polyclonal antibodies against ORF3, the western blot results indicated that 
the specific band at the molecular weight about 11.7kD for cell extracts from Ad_ORF3 was found, but no ORF3 expressing in Ad_GFP was found (Fig. 1c).

\section{Analysis of differentially expressed genes (DEGs) and transcripts}

After the six samples (Ad_GFP_1, Ad_GFP_2, Ad_GFP_3, Ad_ORF3_1, Ad_ORF3_2, and Ad_ORF3_3) passed the quality control test, DNA sequencing was carried out. The raw data generated by sequencing was preprocessed using Cutadpt [16] to filter out the unqualified sequences and produce valid data (clean data). The mapped reads of each sample were assembled using Cufflinks [24]. Then, all transcriptomes from 6 samples were merged to reconstruct a comprehensive transcriptome using Cuffmerge. After the final transcriptome was generated, Cuffdiff was used to estimate the expression levels of all transcripts.

The distribution statistics of genes in each sample were represented by fragments per kilobase of exon model per million mapped reads (FPKM) box charts, and the expression levels of genes were interpreted from the analyses shown in Fig. 2a. The gene expression density distribution of log10 (FPKM) could be used to compare the expression trend of different samples. In this study, the gene expression density distribution of each sample showed a normal distribution, and the gene expression trend of biological repeat samples were consistent (Fig. 2b). All the DEGs were analyzed using volcano plots [25], which provided the overall distribution of the DEGs (Fig. 2c). The results indicated that there were 62 significant DEGs. including 28 upregulated genes and 34 downregulated genes. We identified 6,564 significantly differentially expressed transcripts, including 3,097 upregulated transcripts and 3,467 downregulated transcripts (Fig. 2d and Fig. 2e). Cluster analysis of the DEGs provided a visual display of the gene expression in each sample. To better reflect the cluster expression pattern, we used log10 (FPKM +1$)$ to display gene expression. At the same time, FPKM could be displayed by the $Z$ value. The partial DEGs are shown by a heatmap, in which red indicates upregulated DEGs and dark blue indicates downregulated DEGs (Fig. 2f).

\section{Analysis of differentially expressed IncRNAs}

The software StringTie was used to assemble the reads. Known mRNAs and transcripts less than $200 \mathrm{bp}$ were removed, and then IncRNAs were predicted among the remaining transcripts. The prediction software used comprised CPC and CNCl. FPKM was used to measure the expression levels of the IncRNAs. There were five class codes of IncRNAs, including $\mathrm{i}, \mathrm{j}, \mathrm{o}, \mathrm{u}$, and $\mathrm{x}$ (Fig. 3). The proportions of these five class codes of six samples (Ad_GFP_1, Ad_GFP_2, Ad_GFP_3, Ad_ORF3_1, Ad_ORF3_2, and Ad_ORF3_3) are shown in a pie chart (Fig. 3a).

To show the distribution of IncRNA candidates in the chromosomes more intuitively, we used the software of Circos (www.circos.ca) to map the IncRNAs to the genome. This analysis was mainly divided into two parts. First, genome mapping was carried out according to the different classifications of the IncRNAs. Second, genome mapping was carried out according to the IncRNAs in the different samples. During mapping, each chromosome was analyzed every $25 \mathrm{mb}$ as the basic unit. When the IncRNA- 
related genome in different samples was visualized as a map, the expression of the IncRNAs in each segment was counted. When the genome of different IncRNA types was visualized, the number of IncRNAs in each segment was counted (Fig. 3b).

We identified 319 significantly differentially expressed IncRNAs, including 124 known IncRNAs and 195 novel IncRNAs. Among them, 158 IncRNAs were significantly upregulated and 161 IncRNAs were significantly downregulated (Fig. 3c and Fig. 3d). In the follow-up study, we took the 124 known IncRNAs with significantly differential expression as the research target, and the top 100 known IncRNAs were shown using a heatmap, in which red represented upregulated IncRNAs and dark blue represented downregulated IncRNAs (Fig. 3e).

\section{Comparative analysis of the structural characteristics of differentially expressed IncRNAs and mRNAs}

It has been reported that the structural characteristics (length distribution, the number of exons, and ORF length) and expression levels of IncRNA and mRNA were very different [26]. Therefore, this analysis mainly focused on the structural characteristics and expression levels of IncRNAs and mRNAs. IncRNA and mRNA length statistics and comparisons revealed the percentages of different lengths of transcripts (Fig. 4a).

Although IncRNAs do not have an obvious ORF and cannot encode protein, we compared the IncRNAs and the ORF lengths of the mRNAs to discuss the differences between them. The principle of ORF analysis was based on the six frames translation principle of nucleic acids. The distributions of the ORF lengths of the IncRNAs and mRNAs are shown in Fig. 4b and Fig. 4c. Statistics of IncRNA and mRNA exons are shown in Fig. 4d, and the statistics of IncRNA and mRNA expression levels are shown in Fig. $4 \mathrm{e}$.

\section{Analysis of the interaction between differentially expressed IncRNAs and mRNAs}

There are two kinds of regulation modes of IncRNA, one is cis regulation, i.e., the IncRNA regulates the expression of its neighboring genes. According to the prediction positional relationships, the cis regulatory target genes of IncRNAs were defined as a differentially expressed IncRNA and differentially expressed mRNA within $100 \mathrm{kbp}$ in either direction in the chromosome [27, 28]. The second type of regulation is trans regulation, i.e., the expression of IncRNA cross chromosome regulatory genes, and is difficult to verify in later stages. The target genes of IncRNAs with significantly differential expression were analyzed for functional enrichment using gene ontology GO (http://geneontology.org) and Kyoto Encyclopedia of Genes and Genomes (KEGG) (http://www.kegg.jp/kegg). The top 20 of GO enrichment terms are shown in Fig. 5a; the top $5 \mathrm{GO}$ terms were UDP-glucuronate biosynthetic process, UDP-glucose 6-dehydrogenase activity, transdifferentiation, tetracycline transport, and tetracycline transmembrane transporter activity. The top 20 KEGG enrichment pathways are shown in Fig. $5 \mathrm{~b}$; the top 5 pathways were 
systemic lupus erythematosus, staphylococcus aureus infection, signaling pathways regulating pluripotency of stem cells, the PPAR signaling pathway, and platinum drug resistance.

The significantly differentially expressed mRNAs, including 62 genes and 6,564 transcripts, were used to predict the target genes of the 124 known IncRNAs. In this study, only the upstream and downstream $100 \mathrm{~kb}$ mRNAs and known IncRNAs were predicted for cis regulation. Finally, the target genes prediction results identified 45 IncRNAs corresponding to candidate mRNAs (Table S1).

\section{QRT-PCR validation of partial differentially expressed IncRNAs}

We selected 12 significantly differentially expressed IncRNA ( $p$ value $\leq 0.05$ and $q$ value $\leq 1$ ) for qRTPCR validation, including six upregulated IncRNAs with $\mid \log 2$ fold-change $\mid(|\log 2 \mathrm{FC}|) \geq 2$, and six downregulated IncRNAs with |log2 fold-change $\mid(|\log 2 \mathrm{FC}|) \geq 1$. There were several transcripts for some IncRNAs. GAPDH was used as an internal control. The primers are listed as Table 1. These 12 IncRNAs corresponded to 21 transcripts. Among them, the upregulated IncRNAs were PLCG1-AS1, AL 139099, AC005062, FP236383, FP671120 (ENST00000627981, ENST00000631211) and ZNF337-AS1 (ENST00000428254, ENST00000455791, ENST00000420803, ENST00000421829, ENST00000414393, ENST00000439498); the downregulated IncRNAs were AP005329 (ENST00000581905, ENST00000578800), AP000977, LINC02476 (ENST00000431071, ENST00000426413), RAP2C-AS1 (ENST00000441399, ENST00000421483), AC107959 (ENST00000502083, ENST00000523884), and AC016526. The qRT-PCR validation results showed that the expression patterns eight IncRNAs were consistent with the sequencing data, which indicated that there was a certain number of false-positives in the high-throughput sequencing data (Fig. 6 and Table S2).

\section{Discussion}

SHE is a new type of zoonotic infectious disease, which seriously threatens the development of animal husbandry and public health $[29,30]$. The typical clinical symptoms of SHE are jaundice, and the liver of pigs show pathological changes characteristic of hepatitis. About one week after infection with SHEV, fecal detoxification begins to appear in pigs, which lasts until 55 days after infection. At 14-32 days after infection, symptoms of viremia appear. At 17-24 days after infection, anti-HEV IgM antibodies can be detected. At 3 months after infection, IgG is maintained at a high level. In infected animals, pathological sections show typical manifestations of acute hepatitis [31-33].

HEV ORF3 protein is a viral regulatory protein, which regulates many kinds of cell signaling pathways by targeting the regulatory subunits of p85a that bind to tyrosine kinase Src, phosphatidylinositol 3 kinase, phospholipase $\mathrm{C}$ gamma, and adaptor protein GRB2. However, ORF3 mainly activates the mitogenactivated protein kinase (MAPK) pathway through Src homology 3 domains [34]. ORF3 encodes a phosphorylated protein with unclear function, which promotes the elimination of alpha (1)microglobulin/bikunin precursor (AMBP) in hepatocytes, thus affecting their metabolism [35]. ORF3 is the main factor affecting the outflow of HEV from infected cells, and exists on the surface of the released 
HEV particles, which might be regulated by lipid metabolism [36]. ORF3 is the key to infection in vivo, which might regulate the response of the host. The epidermal growth factor receptor (EGFR) pathway can regulate the signal transduction of endometrial growth factor, thus affecting cell survival. Signal transducer and activator of transcription 3 (STAT3) expression can also be regulated, leading to a significant reduction of the inflammatory response. These findings might provide strong support for the effect of ORF3 on virus replication [37-40]. Taken together, several functions of the ORF3 protein have already been reported. ORF3 interacts with signal transduction pathway proteins by targeting proline rich regions and Src homologous domains. Whether the EGFP-ORF3 fusion protein can still bind to these regions requires further study. LncRNAs are noncoding RNAs with a length of more than 200 nucleotides $[41,42]$. LncRNAs play an important role in many life activities, such as dose compensation effect, epigenetic regulation, cell cycle regulation, and cell differentiation regulation. LncRNAs have become a hot topic in genetic research [43-47].

In this study, we used transcriptome sequencing to identify the significantly differentially expressed IncRNAs and mRNAs in HepG2 cells overexpressing SHEV ORF3. We identified 62 genes and 6,564 transcripts, including 195 novel IncRNAs and 124 known IncRNAs. Among them, we chose the 124 known IncRNAs as our study object, which would be easy to validate and functionally analyze in later research [48]. LncRNA regulation can be divided into two types: cis regulation $[49,50]$ and trans regulation $[27,51]$. We focused on the prediction and analysis of cis regulated differentially expressed mRNAs and IncRNAs.

A previous report used HepG2 and EGFP-expressing HepG2 as controls, and in response to EGFP-ORF3, transcriptome sequencing showed that CLDN6, YLPM1, APOC3, NLRP1, SCARA3, FGA, FGG, FGB, and FREM1 were upregulated, and SLC2A3, DKK1, BPIFB2, and PTGR1 were downregulated [52]. We examined our raw data from the high-throughput sequencing, and examined the 13 previously reported genes one by one. The results showed that CLDN6, YLPM1, APOC3, NLRP1, SCARA3, FGB, FREM1, SLC2A3, DKK1, $B P I F B 2$, and $P T G R 1$ were present in our raw data (Table S3); however, they did not show significantly differential expression. FGA and FGG was not present in our raw data. The possible reasons for these discrepancies were analyzed and summarized. In our study, the latest software, StringTie, was used to assemble and quantify the reads, and edgeR was used to determine difference statistics and perform visual mapping. The highlight of our project is that we analyze the data from the gene and transcript levels, respectively. EdgeR was used for differential analysis ( $\mid$ log 2 fold changel $\geq 1$ (multiple of difference $>2$ times), $p<0.05$ ). At the same time, we provided further definitions or suggestions for the difference threshold according to the initial operation results. Another very important reason is that the expression systems are different. Xu et al. used lentivirus-mediated overexpression of ORF3 in HepG2 cells, screened positive clones using G418, and constructed stable cell lines. However, we used adenovirus directly to mediate high-level overexpression of ORF3 in HepG2 cells. The expression level of ORF3 might affect the differentially expressed genes and their fold change in the target cells. We used adenovirus to mediate the overexpression of ORF3 in HepG2 cells. Although ORF3 is fused with EGFP, whether the function of the EGFP-ORF3 fusion protein is identical to that of native ORF3 requires further experimental verification. As reported before, transcriptome sequencing using HepG2 cells and EGFP expressing-HepG2 cells as negative controls indicated that the expression of EGFP did not interfere with 
the study of ORF3 protein function. The function of IncRNAs can be predicted by the function of their target gene; therefore, the top 20 pathways were predicted by KEGG analysis and comprised systemic lupus erythematosus, staphylococcus aureus infection, signaling pathways regulating pluripotency of stem cells, the PPAR signaling pathway, platinum drug resistance, pentose and glucuronate interconversions, pancreatic cancer, N-Glycan biosynthesis, homologous recombination, herpes simplex virus 1 infection, fat digestion and absorption, the Fanconi anemia pathway, complement and coagulation cascades, central carbon metabolism in cancer, cardiac muscle contraction, carbohydrate digestion and absorption, cAMP signaling pathway, bile secretion, base excision repair, and ascorbate and aldarate metabolism. Among them, we are very interested in the bile secretion pathway, because jaundice is the typical clinical symptom caused by SHEV, and jaundice can only be caused if bile cannot be excreted [52, 53-56]. Bilirubin is an orange-yellow bile pigment, which is the main metabolite of iron porphyrin compounds in vivo and is an important basis for judging jaundice in the clinic. In the smooth endoplasmic reticulum (ER), bilirubin and UDP-glucuronic acid are esterified under the action of glucuronosyl transferase to generate glucuronosyl bilirubin, which is then excluded from the liver together with bile under the action of Golgi bodies and lysosomes. However, bilirubin metabolism disorder leads to jaundice, and the typical clinical symptom of SHE is jaundice [57-59]. Therefore, SHEV-ORF3 might affect the pentose and glucuronate interconversions of the above top 20 pathways and mediate the occurrence of jaundice. The obstruction of the bile excretion channel leads to increased internal pressure in the bile duct and capillaries, which leads to the reverse flow of glucuronide bilirubin into the blood and the increase of serum bilirubin concentration, leading to obstructive jaundice [60-62]. Therefore, SHEVORF3 might also mediate the formation of obstructive jaundice by influencing the bile secretion of the above top 20 pathways. These two pathways will be studied in our follow-up experiments, and might represent a new direction to elucidate the pathogenesis of SHEV.

In the present study, we identified the IncRNA and mRNA differential expression profiles in HepG2 cells overexpressing SHEV ORF3. The structures of the IncRNAs were compared with those of the mRNAs, and

the functional enrichment of target genes was analyzed using GO and KEGG, which revealed the possible functions of the IncRNAs. The qRT-PCR validation results demonstrated that the sequencing data was reliable. In the future, we will investigate the pathogenesis of SHEV by studying the significantly differentially expressed of IncRNAs and their regulatory target genes.

\section{Conclusions}

SHEV-ORF3 might affect the pentose and glucuronate interconversions and mediate the formation of obstructive jaundice by influencing the bile secretion. Our findings are of great significance in revealing the function of SHEV ORF3 and explaining the molecular mechanism of SHEV pathogenesis.

\section{Abbreviations}

SHEV: Swine hepatits E virus; ORF3: open reading frame; IncRNA: long non-coding RNA; DMEM: Dulbecco's modified Eagle's medium; FBS: fetal bovine serum; NC: negative control; FPKM: fragments per 
kilobase of exon model per million mapped reads; GO: gene ontology; KEGG: Kyoto Encyclopedia of Genes and Genomes.

\section{Declarations}

\section{Acknowledgements}

Not applicable.

\section{Authors' contributions}

$\mathrm{HJ}, \mathrm{QH}, \mathrm{JC}, \mathrm{LG}$ and $\mathrm{XL}$ contributed to conception and design of the study. $\mathrm{HJ}, \mathrm{XS}$ and $\mathrm{YL}$ contributed to data acquisition and data analysis. ZZ, YZ and WL contributed to data interpretation. HJ, BL and GG drafted the manuscript. HJ and LW revised the manuscript. All authors have read and approved the final version of themanuscript.

\section{Funding}

This study was financially supported by the Chongqing Research Program of Basic Research and Frontier Technology (cstc2018jcyjA0807), the Natural Science Foundation of Chongqing (cstc2020jcyjmsxm0522), the Fundamental Research Funds for the Central Universities (XDJK2020C022, XDJK2019C024), and the National Science Foundation for Young Scientists of China (31802215).

\section{Availability of data and materials}

The sequencing data of all experimental samples in the fastq format have been submitted to the Sequence Read Archive of NCBI under the accession number GSE147129.

\section{Ethics approval and consent to participate}

Not applicable.

\section{Consent for publication}

Not applicable.

\section{Competing interests}

The authors declare that they have no competing interests

\section{References}

1. Nan Y, Wu C, Zhao Q, Sun Y, Zhang YJ, Zhou EM. Vaccine Development against Zoonotic Hepatitis E Virus: Open Questions and Remaining Challenges. Front Microbiol. 2018;9:266. 
2. Chowdhury AD, Takemura K, Li TC, Suzuki T, Park EY. Electrical pulse-induced electrochemical biosensor for hepatitis E virus detection. Nat Commun. 2019;10(1):3737.

3. Gallian P, Pouchol E, Djoudi R, Lhomme S, Mouna L, Gross S, et al. Transfusion-Transmitted Hepatitis E Virus Infection in France. Transfus Med Rev. 2019;33(3):146-53.

4. Fousekis FS, Mitselos IV, Christodoulou DK. Extrahepatic manifestations of hepatitis E virus: An overview. Clin Mol Hepatol. 2020;26(1):16-23.

5. Soon CF, Zhang S, Suneetha PV, Antunes DA, Manns MP, Raha S, et al. Hepatitis E Virus (HEV)Specific T Cell Receptor Cross-Recognition: Implications for Immunotherapy. Front Immunol. 2019;10:2076.

6. Ukuli AQ, Mugimba KK. Seroprevalence of hepatitis E in swine abattoir workers. Afr Health Sci. 2017;17(4):1022-8.

7. Salines M, Andraud M, Terrade F, Rose N. Are French pig farmers and veterinarians knowledgeable about emerging foodborne pathogens? The case of hepatitis E virus. Prev Vet Med. 2018;156:1-7.

8. Ward P, Poitras E, Leblanc D, Letellier A, Brassard J, Plante D, et al. Comparative analysis of different TaqMan real-time RT-PCR assays for the detection of swine Hepatitis E virus and integration of Feline calicivirus as internal control. J Appl Microbiol. 2009;106(4):1360-9.

9. Shu Y, Chen Y, Zhou S, Zhang S, Wan Q, Zhu C, et al. Cross-sectional Seroprevalence and Genotype of Hepatitis E Virus in Humans and Swine in a High-density Pig-farming Area in Central China. Virol Sin. 2019;34(4):367-76.

10. Cao D, Cao QM, Subramaniam S, Yugo DM, Heffron CL, Rogers AJ, et al. Pig model mimicking chronic hepatitis E virus infection in immunocompromised patients to assess immune correlates during chronicity. Proc Natl Acad Sci U S A. 2017;114(27):6914-23.

11. Gouttenoire J, Pollán A, Abrami L, Oechslin N, Mauron J, Matter M, et al. Palmitoylation mediates membrane association of hepatitis E virus ORF3 protein and is required for infectious particle secretion. PLoS Pathog. 2018;14(12):e1007471.

12. Ding Q, Heller B, Capuccino JM, Song B, Nimgaonkar I, Hrebikova G, et al. Hepatitis E virus ORF3 is a functional ion channel required for release of infectious particles. Proc Natl Acad Sci U S A. 2017;114(5):1147-52.

13. Lei Q, Li L, Cai J, Huang W, Qin B, Zhang S. ORF3 of Hepatitis E Virus Inhibits the Expression of Proinflammatory Cytokines and Chemotactic Factors in LPS-Stimulated Human PMA-THP1 Cells by Inhibiting NF-KB Pathway. Viral Immunol. 2016;29(2):105-11.

14. Kenney SP, Wentworth JL, Heffron CL, Meng XJ. Replacement of the hepatitis E virus ORF3 protein PxxP motif with heterologous late domain motifs affects virus release via interaction with TSG101. Virology. 2015;486:198-208.

15. Martin M. Cutadapt removes adapter sequences from high-throughput sequencing reads. EMBnet J. 2011;17:10-2.

16. Langmead B, Salzberg SL. Fast gapped-read alignment with Bowtie 2. Nat Methods. 2012;9(4):3579. 
17. Kim D, Langmead B, Salzberg SL. HISAT: a fast spliced aligner with low memory requirements. Nat Methods. 2015;12(4):357-60.

18. Pertea M, Pertea GM, Antonescu CM, Chang TC, Mendell JT, Salzberg SL. StringTie enables improved reconstruction of a transcriptome from RNA-seq reads. Nat Biotechnol. 2015;33(3):290-5.

19. Robinson MD, McCarthy DJ, Smyth GK. edgeR: a Bioconductor package for differential expression analysis of digital gene expression data. Bioinformatics. 2010;26(1):139-40.

20. Kong L, Zhang Y, Ye ZQ, Liu XQ, Zhao SQ, Wei L, et al. CPC: assess the protein-coding potential of transcripts using sequence features and support vector machine. Nucleic Acids Res. 2007;35:W3459. (Web Server issue).

21. Sun L, Luo H, Bu D, Zhao G, Yu K, Zhang C, et al. Utilizing sequence intrinsic composition to classify protein-coding and long non-coding transcripts. Nucleic Acids Res. 2013;41(17):e166.

22. Trapnell C, Williams BA, Pertea G, Mortazavi A, Kwan G, van Baren MJ, et al. Transcript assembly and quantification by RNA-Seq reveals unannotated transcripts and isoform switching during cell differentiation. Nat Biotechnol. 2010;28(5):511-5.

23. Conesa A, Götz S, García-Gómez JM, Terol J, Talón M, Robles M. Blast2GO: a universal tool for annotation, visualization and analysis in functional genomics research. Bioinformatics. 2005;21(18):3674-6.

24. Trapnell C, Roberts A, Goff L, Pertea G, Kim D, Kelley DR, et al. Differential gene and transcript expression analysis of RNA-seq experiments with TopHat and Cufflinks. Nat Protoc. 2012;7(3):56278.

25. Li W. Volcano plots in analyzing differential expressions with mRNA microarrays. J Bioinform Comput Biol. 2012;10(6):1231003.

26. Wang Y, Xue S, Liu X, Liu H, Hu T, Qiu X, et al. Analyses of Long Non-Coding RNA and mRNA profiling using RNA sequencing during the pre-implantation phases in pig endometrium. Sci Rep. 2016;6:20238.

27. Yan P, Luo S, Lu JY, Shen X. Cis- and trans-acting IncRNAs in pluripotency and reprogramming. Curr Opin Genet Dev. 2017;46:170-8.

28. Ghosal S, Das S, Chakrabarti J. Long noncoding RNAs: new players in the molecular mechanism for maintenance and differentiation of pluripotent stem cells. Stem Cells Dev. 2013;22(16):2240-53.

29. Mesquita JR, Istrate C, Santos-Ferreira NL, Ferreira AS, Abreu-Silva J, Veiga J, et al. Short communication: detection and molecular characterization of hepatitis $E$ virus in domestic animals of São Tomé and Príncipe. Trop Anim Health Prod. 2019;51(2):481-5.

30. Syed SF, Zhao Q, Umer M, Alagawany M, Ujjan IA, Soomro F, et al. Past, present and future of hepatitis E virus infection: Zoonotic perspectives. Microb Pathog. 2018;119:103-8.

31. Wang L, Liu L, Wei Y, Wang Q, Tian Q, Wang L, et al. Clinical and virological profiling of sporadic hepatitis E virus infection in China. J Infect. 2016;73(3):271-9. 
32. Go HJ, Park BJ, Ahn HS, Lyoo EL, Kim DH, Lee JB, et al. Identification of Hepatitis E Virus in Bovine and Porcine Raw Livers. J Microbiol Biotechnol. 2019;29(12):2022-5.

33. Mirazo S, Gardinali NR, Cecilia D, Verger L, Ottonelli F, Ramos N, et al. Serological and virological survey of hepatitis E virus (HEV) in animal reservoirs from Uruguay reveals elevated prevalences and a very close phylogenetic relationship between swine and human strains. Vet Microbiol. 2018;213:21-7.

34. Korkaya H, Jameel S, Gupta D, Tyagi S, Kumar R, Zafrullah M, et al. The ORF3 protein of hepatitis E virus binds to Src homology 3 domains and activates MAPK. J Biol Chem. 2001;276(45):42389-400.

35. Tyagi S, Surjit M, Roy AK, Jameel S, Lal SK. The ORF3 protein of hepatitis E virus interacts with liverspecific alpha1-microglobulin and its precursor alpha1-microglobulin/bikunin precursor (AMBP) and expedites their export from the hepatocyte. J Biol Chem. 2004;279(28):29308-19.

36. Yamada K, Takahashi M, Hoshino Y, Takahashi H, Ichiyama K, Nagashima S, et al. ORF3 protein of hepatitis E virus is essential for virion release from infected cells. J Gen Virol. 2009;90(Pt 8):188091.

37. Chandra V, Kar-Roy A, Kumari S, Mayor S, Jameel S. The hepatitis E virus ORF3 protein modulates epidermal growth factor receptor trafficking, STAT3 translocation, and the acute-phase response. J Virol. 2008;82(14):7100-10.

38. Parvez MK, Al-Dosari MS. Evidence of MAPK-JNK1/2 activation by hepatitis E virus ORF3 protein in cultured hepatoma cells. Cytotechnology. 2015;67(3):545-50.

39. Kenney SP, Pudupakam RS, Huang YW, Pierson FW, LeRoith T, Meng XJ. The PSAP motif within the ORF3 protein of an avian strain of the hepatitis $E$ virus is not critical for viral infectivity in vivo but plays a role in virus release. J Virol. 2012;86(10):5637-46.

40. Lei Q, Li L, Zhang S, Li T, Zhang X, Ding X, et al. HEV ORF3 downregulates TLR7 to inhibit the generation of type I interferon via impairment of multiple signaling pathways. Sci Rep. 2018;8(1):8585.

41. Smith KN, Miller SC, Varani G, Calabrese JM, Magnuson T. Multimodal Long Noncoding RNA Interaction Networks: Control Panels for Cell Fate Specification. Genetics. 2019;213(4):1093-110.

42. Caley DP, Pink RC, Trujillano D, Carter DR. Long noncoding RNAs, chromatin, and development. ScientificWorldJournal. 2010;10:90-102.

43. Chi Y, Wang D, Wang J, Yu W, Yang J. Long Non-Coding RNA in the Pathogenesis of Cancers. Cells. 2019;8(9).

44. Zhao J, Li L, Han ZY, Wang ZX, Qin LX. Long noncoding RNAs, emerging and versatile regulators of tumor-induced angiogenesis. Am J Cancer Res. 2019;9(7):1367-81.

45. Pirogov SA, Gvozdev VA, Klenov MS. Long Noncoding RNAs and Stress Response in the Nucleolus. Cells. 2019;8(7).

46. Agliano F, Rathinam VA, Medvedev AE, Vanaja SK, Vella AT. Long Noncoding RNAs in Host-Pathogen Interactions. Trends Immunol. 2019;40(6):492-510. 
47. Yao RW, Wang Y, Chen LL. Cellular functions of long noncoding RNAs. Nat Cell Biol. 2019;21(5):54251.

48. Benhammou JN, Ko A, Alvarez M, Kaikkonen MU, Rankin C, Garske KM, et al. Novel Lipid Long Intervening Noncoding RNA, Oligodendrocyte Maturation-Associated Long Intergenic Noncoding RNA, Regulates the Liver Steatosis Gene Stearoyl-Coenzyme A Desaturase As an Enhancer RNA. Hepatol Commun. 2019;3(10):1356-72.

49. Gao Z, Chen M, Tian X, Chen L, Chen L, Zheng X, et al. A novel human IncRNA SANT1 cis-regulates the expression of SLC47A2 by altering SFPQ/E2F1/HDAC1 binding to the promoter region in renal cell carcinoma. RNA Biol. 2019;16(7):940-9.

50. Lu Z, Li Y, Che Y, Huang J, Sun S, Mao S, et al. The TGFß-induced IncRNA TBILA promotes non-small cell lung cancer progression in vitro and in vivo via cis-regulating HGAL and activating S100A7/JAB1 signaling. Cancer Lett. 2018;432:156-68.

51. Carmona S, Lin B, Chou T, Arroyo K, Sun S. LncRNA Jpx induces Xist expression in mice using both trans and cis mechanisms. PLoS Genet. 2018;14(5):e1007378.

52. Xu K, Guo S, Zhao T, Zhu H, Jiao H, Shi Q, et al. Transcriptome Analysis of HepG2 Cells Expressing ORF3 from Swine Hepatitis E Virus to Determine the Effects of ORF3 on Host Cells. Biomed Res Int. 2016;2016:1648030.

53. Klimczak T, Kaczka K, Klimczak J, Tyczkowska-Sieroń E, Tyczkowska A. "Primary bacterial culture of bile and pancreatic juice in tumor related jaundice (TROJ) - is ascending cholangitis always our fault?". Scand J Gastroenterol. 2018;53(12):1569-74.

54. Yang R, Zhu S, Pischke SE, Haugaa H, Zou X, Tonnessen TI. Bile and circulating HMGB1 contributes to systemic inflammation in obstructive jaundice. J Surg Res. 2018;228:14-9.

55. Shestopalov SS, Mikhaylova SA, Abramov El, Ozhigina EV. [Malignant obstructive jaundice management via external biliary drainage followed by bile examination]. Khirurgiia (Mosk). 2018(10):44-50.

56. Ji CG, Xie XL, Yin J, Qi W, Chen L, Bai Y, et al. Bile acid receptor TGR5 overexpression is associated with decreased intestinal mucosal injury and epithelial cell proliferation in obstructive jaundice. Transl Res. 2017;182:88-102.

57. Weeramange CJ, Binns CM, Chen C, Rafferty RJ. Inhibition of UDP-glucose dehydrogenase by 6thiopurine and its oxidative metabolites: Possible mechanism for its interaction within the bilirubin excretion pathway and 6TP associated liver toxicity. J Pharm Biomed Anal. 2018;151:106-15.

58. Babaoglu MO, Yigit S, Aynacioglu AS, Kerb R, Yurdakok M, Bozkurt A. Neonatal jaundice and bilirubin UDP-glucuronosyl transferase 1A1 gene polymorphism in Turkish patients. Basic Clin Pharmacol Toxicol. 2006;98(4):377-80.

59. Sugatani J, Kojima H, Ueda A, Kakizaki S, Yoshinari K, Gong QH, et al. The phenobarbital response enhancer module in the human bilirubin UDP-glucuronosyltransferase UGT1A1 gene and regulation by the nuclear receptor CAR. Hepatology. 2001;33(5):1232-8. 
60. Costas-Rodríguez M, Van Campenhout S, Hastuti A, Devisscher L, Van Vlierberghe H, Vanhaecke F. Body distribution of stable copper isotopes during the progression of cholestatic liver disease induced by common bile duct ligation in mice. Metallomics. 2019;11(6):1093-103.

61. Block J. Nineteenth-Century Homeopathic Repertories Predict Increased Urinary Excretion of Bile in Cholestasis but Not in Non-Cholestatic Infant Jaundice. Homeopathy. 2019;108(4):270-6.

62. Ishizawa $M$, Ogura $M$, Kato $S$, Makishima M. Impairment of bilirubin clearance and intestinal interleukin-6 expression in bile duct-ligated vitamin D receptor null mice. PLoS One. 2012;7(12):e51664.

\section{Figures}


A
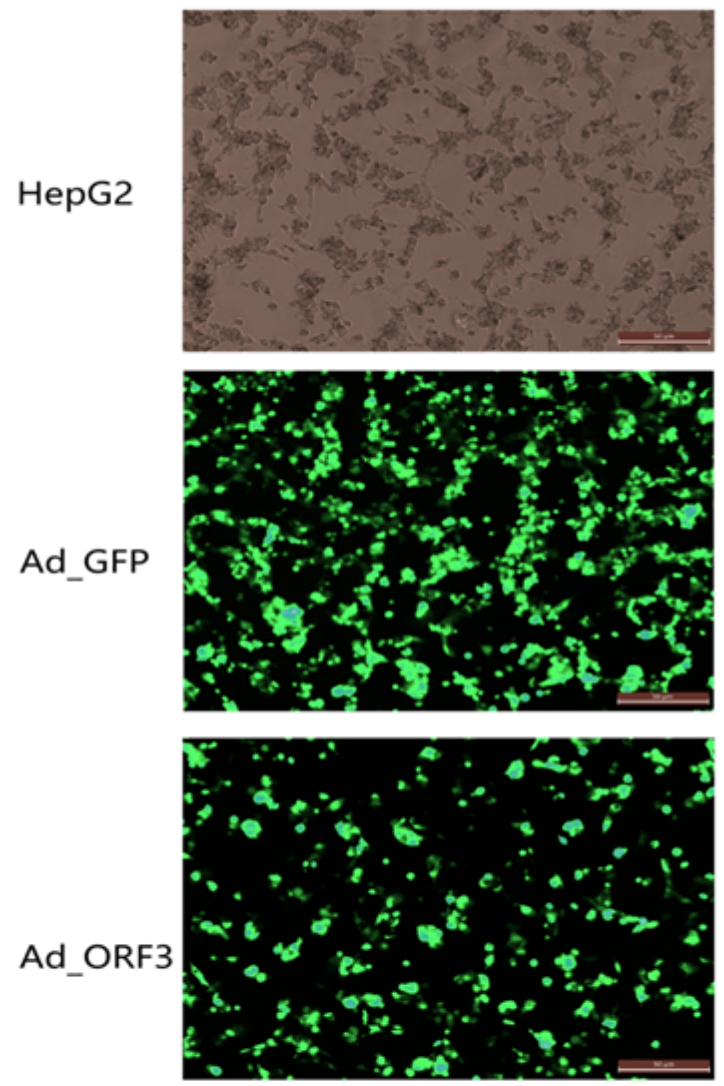

B

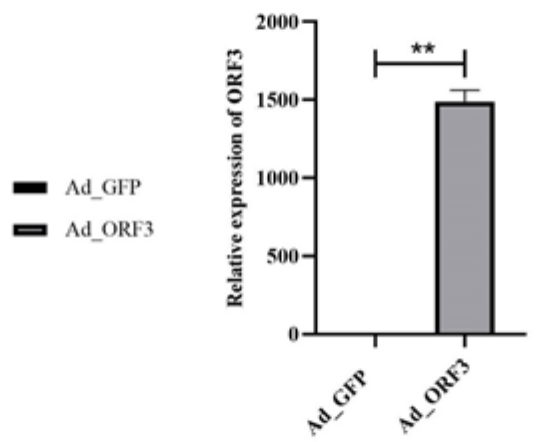

C

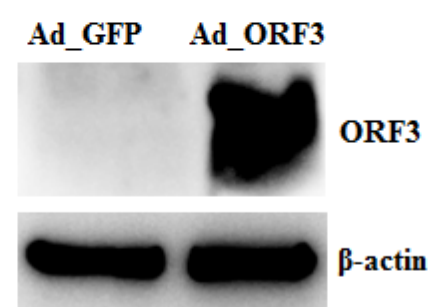

\section{Figure 1}

Adenovirus of ADV4-ORF3 and ADV4-NC mediated overexpression of ORF3 in HepG2 cells. a Fluorescence microscope observation of HepG2 cells infected by adenovirus of ADV4-ORF3 and ADV4$\mathrm{NC}$ for $24 \mathrm{~h}$. b qRT-PCR validation for the relative expression level of ORF3. c Western-blot analysis of HepG2 cells infected by adenovirus of ADV4-ORF3 and ADV4-NC for $24 \mathrm{~h}$ with rabbit polyclonal antibody against ORF3. $\beta$-actin was used for an internal control. 
A

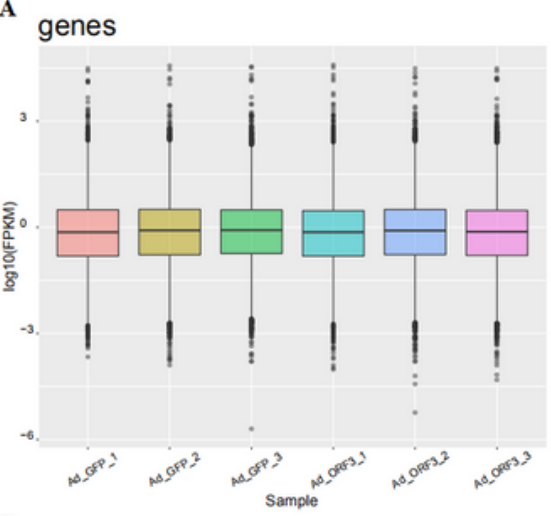

B genes

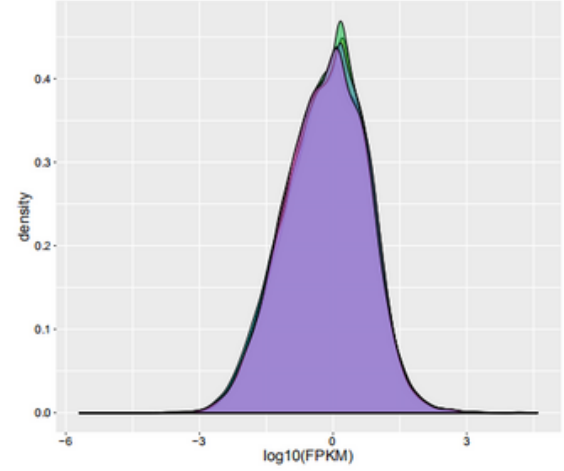

E

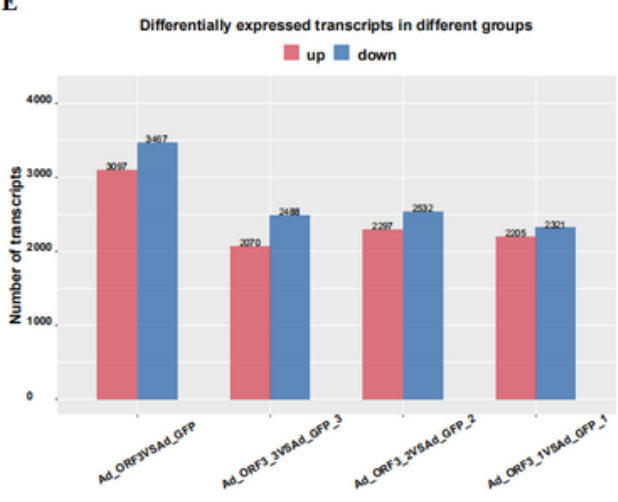

C Ad_ORF3VSAd_GFP

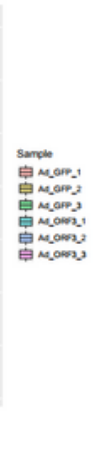

D

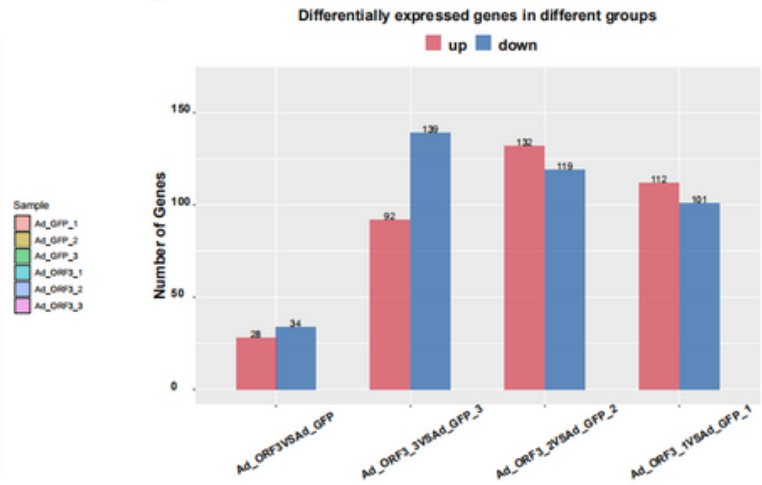

$\mathbf{F}$

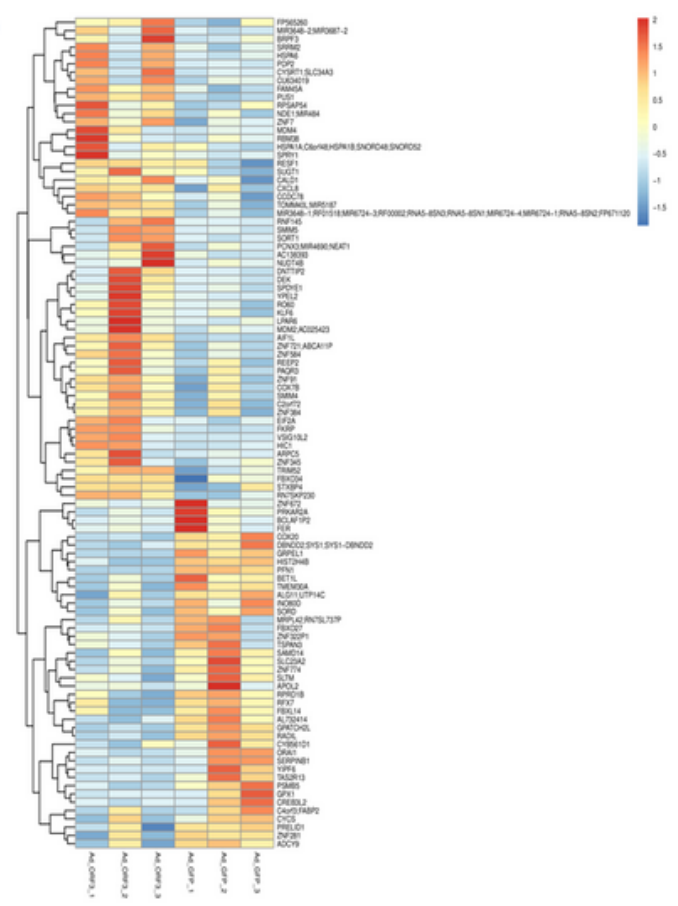

\section{Figure 2}

Analysis of differentially expressed genes (DEGs) and transcripts. a Distribution of gene expression values for each sample. The $x$-axis is the sample name and the $y$-axis is log10 (fragments per kilobase of exon model per million mapped reads (FPKM)). The box graph of each region corresponds to five statistics (the maximum, the upper quartile, the median, the lower quartile, and the minimum respectively from the top to the bottom). b Gene expression density distribution. The x-axis is the log10 (FPKM) and 
the $y$-axis shows the gene expression density. c Volcano analysis of differential expression levels of genes; the $x$-axis is log2 (fold change), which represents the variation of the differential expression of multiple genes in different samples, and the Y-axis shows the -log10 ( $p$ value), which represents the statistical significance of the change in the gene expression levels; red indicates upregulated DEGs and dark blue indicates downregulated DEGs. $d$ The statistics of the frequency of up and downregulation of genes with significantly differential expression. Red represents upregulated genes and dark blue represents downregulated genes. e The statistics of the frequency of up and downregulated transcripts with significant differential expression. Red represents upregulated transcripts and dark blue represents downregulated transcripts. $f$ Heatmap of partial DEGs; red indicates upregulated DEGs and dark blue indicates downregulated DEGs. 
A

Ad_GFP_1
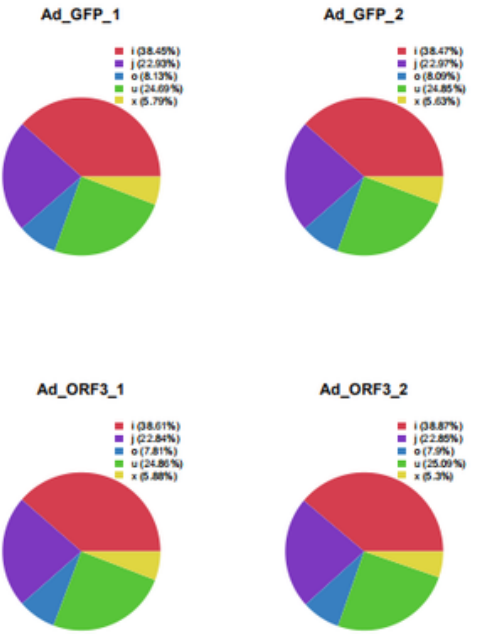

C Ad_ORF3VSAd_GFP

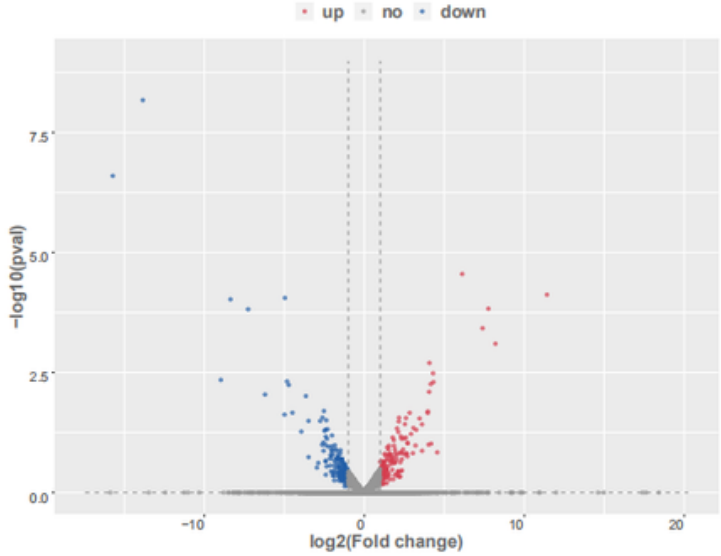

D

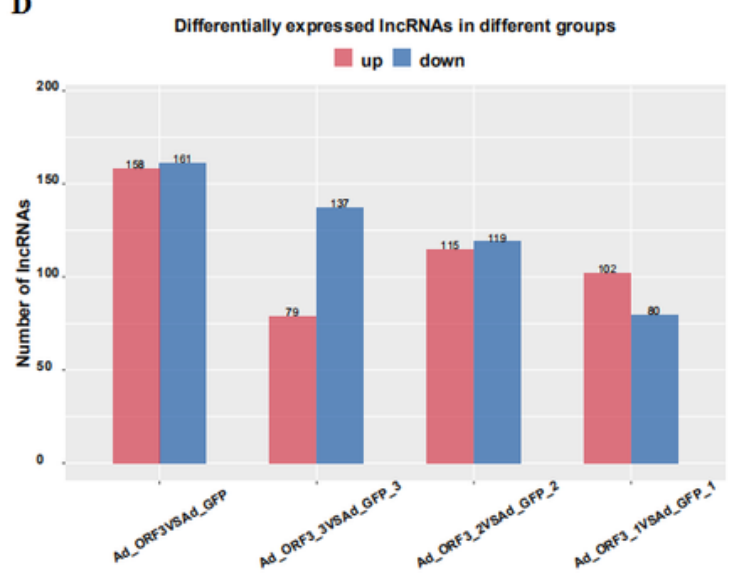

B

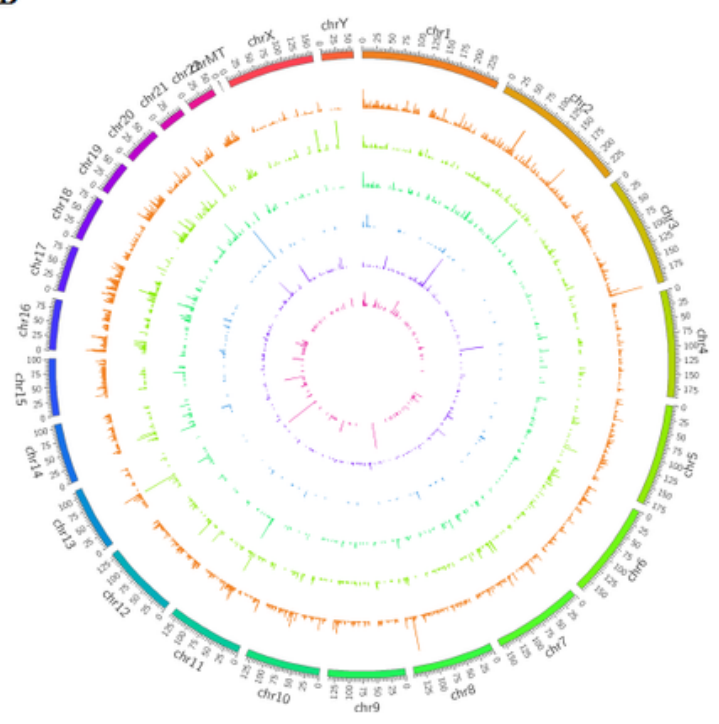

$\mathbf{E}$

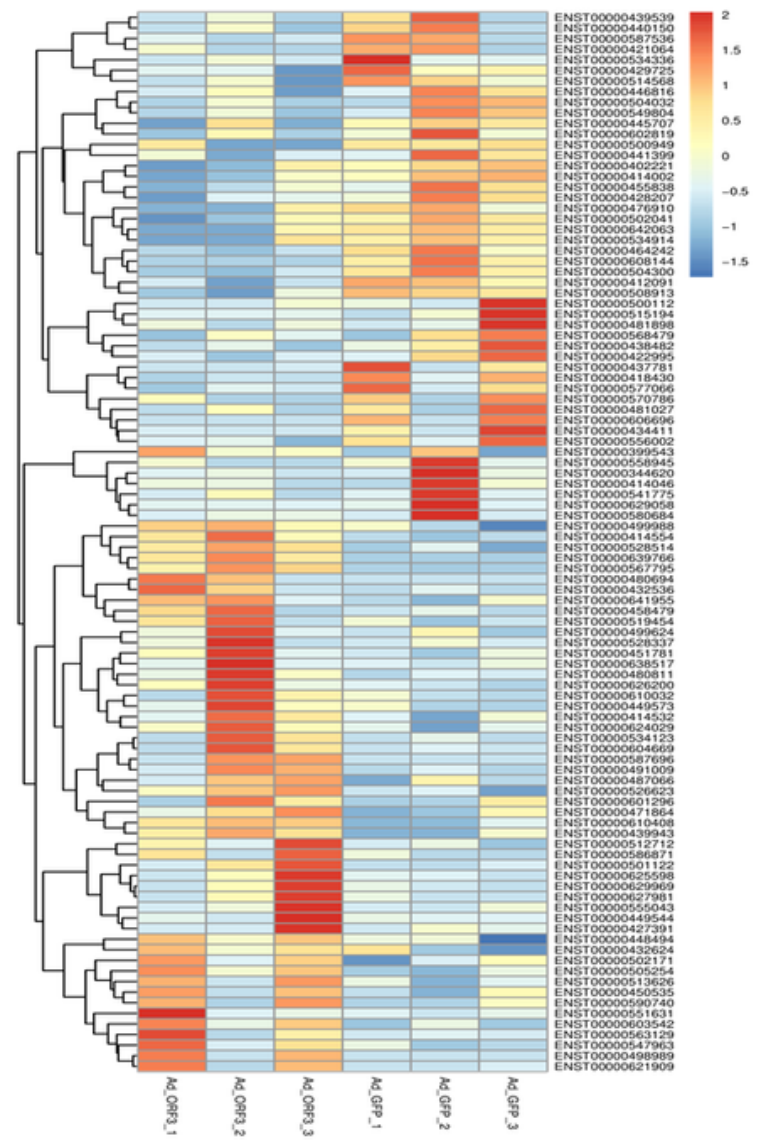

\section{Figure 3}

Analysis of differentially expressed long noncoding RNAs (IncRNAs). a Pie chart of different class code proportions of the IncRNAs in each sample. There are five class code of IncRNA: J indicates a potentially novel isoform (fragment); i indicates a transfragment falling entirely within a reference intron; o indicates generic exonic overlap with a reference transcript; $u$ indicates an unknown, intergenic transcript; and $x$ indicates exonic overlap with the reference on the opposite strand. b Visualization results of IncRNAs 
from different samples, showing the distribution of IncRNA candidates in the chromosome more intuitively. c Volcano analysis of differentially expressed IncRNA levels; the $x$-axis is log2 (fold change) and the $y$-axis was - $\log 10$ ( $p$ value). Red represents upregulated IncRNAs and dark blue represents downregulated IncRNAs. d Statistics of the frequency of up and downregulated IncRNAs with significant differential expression. Red represents upregulated IncRNAs and dark blue represent down-regulated IncRNAs. e Heat map of differentially expressed IncRNAs; red represents up-regulated IncRNAs and dark blue represents downregulated IncRNAs.
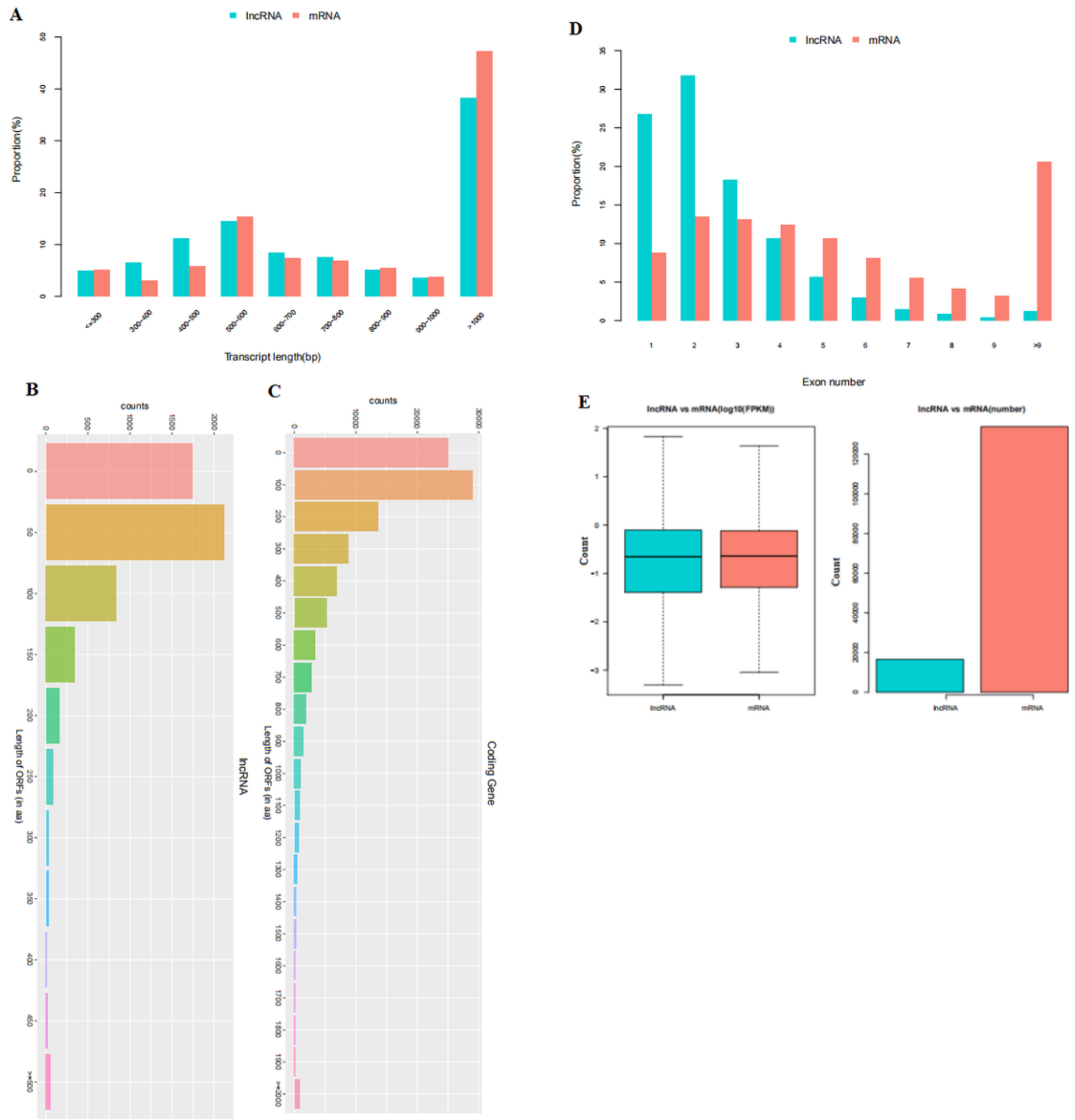


\section{Figure 4}

Analysis of the structural characteristics of differentially expressed long noncoding RNAs (IncRNAs) and mRNAs. a LncRNA and mRNA length statistics and comparisons; the $x$-axis represents the transcript length, and the $y$-axis represents the proportion. b Distribution of the ORF lengths of IncRNAs. C Distribution of the ORF lengths of mRNAs. $d$ Statistics of IncRNA and mRNA exons. The x-axis represents the exon number of the IncRNA and mRNA, and the $y$-axis represents the proportion. e LncRNA and mRNA expression levels were statistically analyzed from two levels of log10 (fragments per kilobase of exon model per million mapped reads (FPKM)) and number.

A

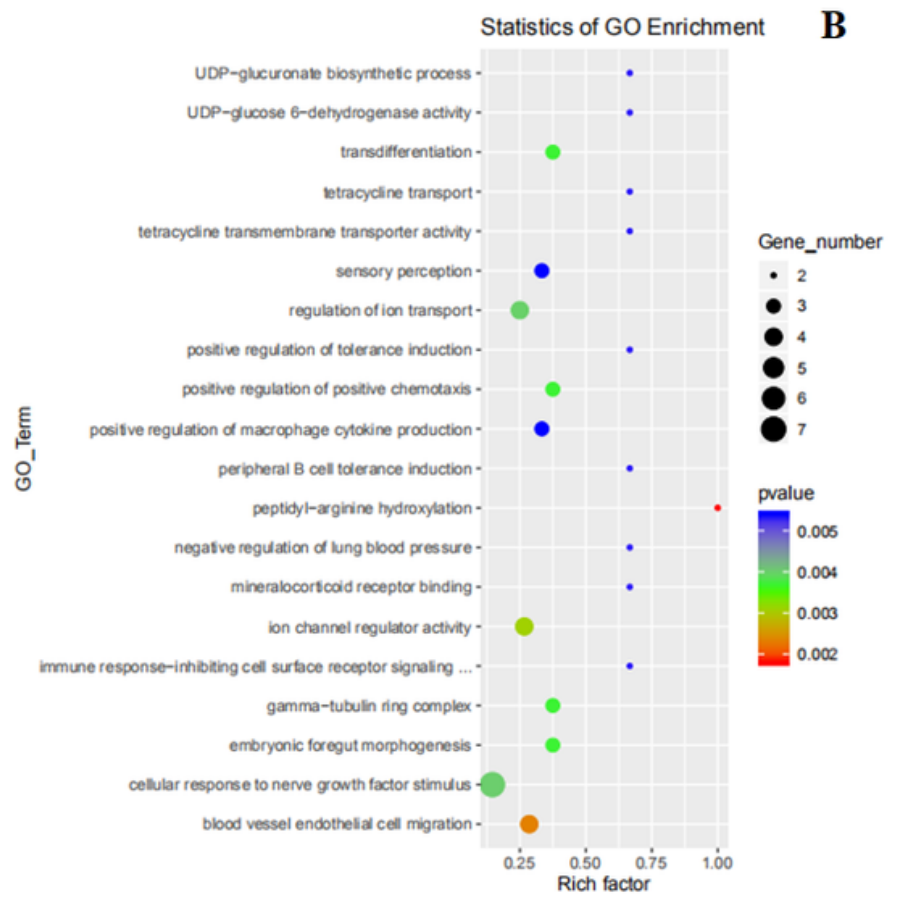

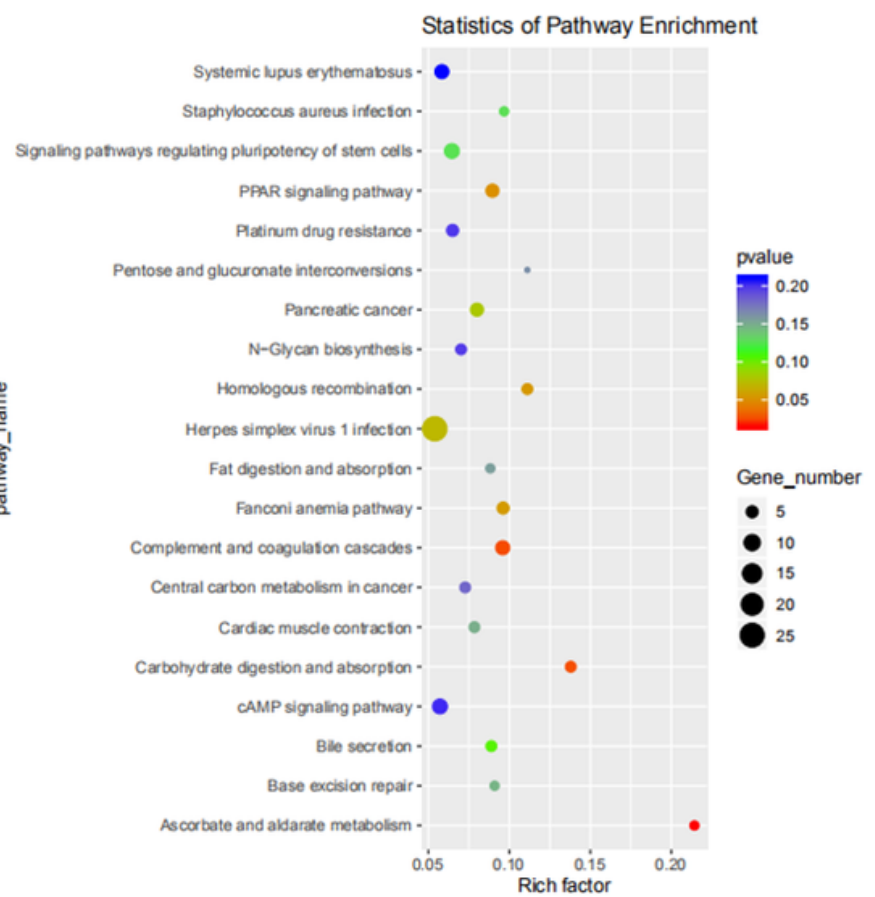

\section{Figure 5}

Analysis of the functional enrichment of target genes of the significantly differentially expressed long noncoding RNAs (IncRNAs). a Gene ontology (GO) functional enrichment analysis of the predicted target genes of the differentially expressed IncRNAs. $y$-axis: GO terms; $x$-axis: Rich factor. The color of each bubble represents the $p$ value, and the bubble size represents the gene number. $b$ Kyoto Encyclopedia of Genes an Genomes (KEGG) pathway enrichment analysis of the predicted target genes of the differentially expressed IncRNAs. y-axis: Pathway name; $x$-axis: Rich factor. The color of each bubble represents the $p$ value, and the bubble size represents the gene number. 

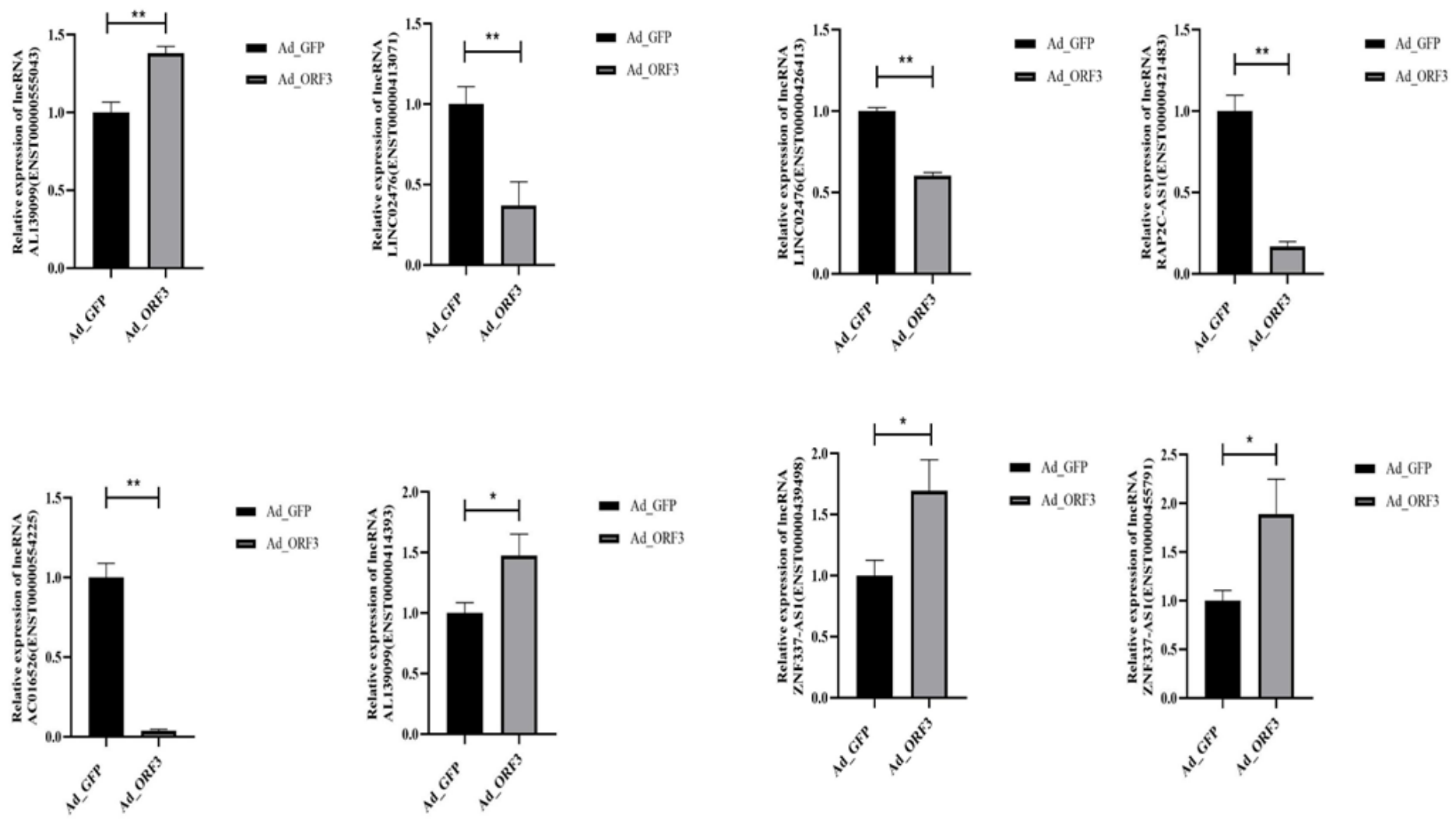

Figure 6

Quantitative real-time reverse transcription PCR (qRT-PCR) validation for the eight selected significantly

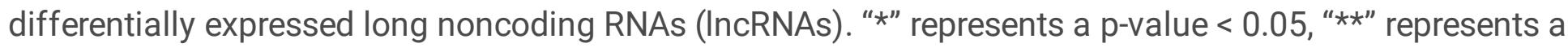
p-value $<0.01$.

\section{Supplementary Files}

This is a list of supplementary files associated with this preprint. Click to download.

- supplementaryfile1.Tif

- supplementaryfile2.Tif

- Tables1S3.docx 